\title{
Jean de Roye, Chronique scandaleuse. Journal d'un Parisien au temps de Louis XI
}

\section{Maria Colombo Timelli}

\section{(2) OpenEdition}

1 Journals

\section{Édition électronique}

URL : http://journals.openedition.org/studifrancesi/5266

DOI : 10.4000/studifrancesi.5266

ISSN : 2427-5856

Éditeur

Rosenberg \& Sellier

\section{Édition imprimée}

Date de publication : 1 décembre 2016

Pagination : $511-512$

ISSN : 0039-2944

\section{Référence électronique}

Maria Colombo Timelli, « Jean de Roye, Chronique scandaleuse. Journal d"un Parisien au temps de Louis XI », Studi Francesi [En ligne], 180 (LX | III) | 2016, mis en ligne le 01 janvier 2017, consulté le 17 septembre 2020. URL : http://journals.openedition.org/studifrancesi/5266 ; DOI : https://doi.org/ 10.4000/studifrancesi.5266

Ce document a été généré automatiquement le 17 septembre 2020.

\section{(c)}

Studi Francesi è distribuita con Licenza Creative Commons Attribuzione - Non commerciale - Non opere derivate 4.0 Internazionale. 


\title{
Jean de Roye, Chronique scandaleuse. Journal d'un Parisien au temps de Louis $X I$
}

\author{
Maria Colombo Timelli
}

\section{RÉFÉRENCE}

JEAN DE ROYE, Chronique scandaleuse. Journal d'un Parisien au temps de Louis XI, Traduit et présenté par Joël Blanchard, Paris, Pocket, 2015, 382 pp.

1 Malgré la volonté de Jean de Roye lui-même, qui ne voulait pas qu'on intitule chroniques son journal, c'est bien le titre tardif choisi par un éditeur anonyme en 1611 qui s'est imposé par la suite: «Histoire de Louys unziesme, roy de France... autrement dite la Chronique Scandaleuse...». L'auteur, notaire au Châtelet de Paris, se proposait de fait de rédiger une sorte d'histoire urbaine, qui ne peut ignorer quelques grands évènements (de l'entrée de Louis XI en 1461 à la défaite des Bourguignons en 1477), mais fait la part belle au quotidien (de l'anticipation des vendanges à Paris en 1465 à la canicule de l'année suivante).

2 L'Introduction de Joël Blanchard est consacrée quasi entièrement à une présentation de la capitale sous Louis XI et aux thématiques abordées par Jean de Roye, alors qu'elle passe quasiment sous silence l'histoire de la transmission de son texte, qui a manifestement attiré des lecteurs pendant plus d'un siècle. De fait, si deux seuls manuscrits sont conservés (Paris, BnF, fr. 5062, qui porte la signature de l'auteur et se termine en mars 1479; et BnF, fr. 2889, qui prolonge le récit jusqu'en août de la même année), le passage à l'imprimé fut presque immédiat (Lyon, ca 1488-1490), et d'autres éditions suivirent jusqu'en 1620 .

3 En effet, ce qui fait sans doute l'intérêt de cette chronique tient justement à la «myopie» de son auteur, qui relate essentiellement les évènements parisiens auxquels il a assisté personnellement ou dont il a entendu parler; certes, de grands personnages 
défilent sous les yeux du lecteur (le roi de France, Louis de Luxembourg, Charles le Téméraire entre bien d'autres), mais souvent c'est la petite histoire qui passe au premier plan: Jean de Roye s'intéresse alors aux manifestations spectaculaires (fêtes, processions, joutes), ainsi qu'aux aspects judiciaires (procès, condamnations, exécutions capitales, sur lesquels il jouit d'informations de première main), et économiques (les marchandises, leur circulation, leur prix). Selon les mots de Joël Blanchard, la Chronique est «un témoignage de première main de la vie publique parisienne» de la seconde moitié $d u \mathrm{Xv}^{\mathrm{e}}$ siècle (p. 38), période trouble et difficile dont elle nous permet surtout de découvrir des usages et des mœurs que les grandes Chroniques du temps négligent. Son charme vient en partie, nous semble-t-il, du contraste entre les deux faces d'une même médaille: pour ne donner qu'un exemple, deux petites pages séparent la condamnation de trois sergents qui avaient battu et blessé un prêtre et l'évocation de la mort de Philippe le Bon (p. 153 et 155 respectivement).

4 Joël Blanchard fournit une traduction très claire, basée pour l'essentiel sur le ms. fr. 5062, qu'il complète, pour les évènements postérieurs à 1479, par le deuxième manuscrit et par l'incunable. Des notes en bas de page, aussi nombreuses que riches, fournissent les informations essentielles pour la compréhension du texte, et les titres courants permettent même au lecteur le moins averti de suivre le rythme des évènements; s'y ajoute un précieux index des noms de personne et de lieu (pp. 359-382), qui permet entre autres de mesurer la récurrence de certains personnages et donc leur importance sous la plume de Jean de Roye. 